
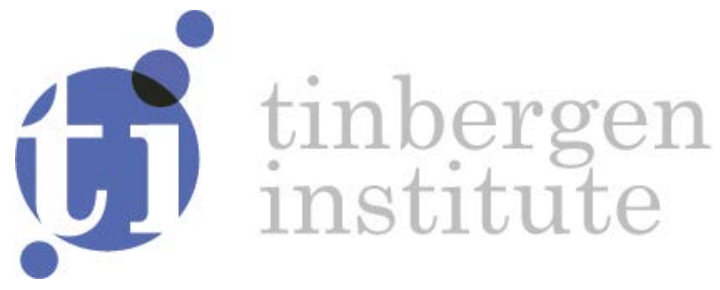

\title{
Intermediation Services and Search Frictions
}

Christian Holzner ${ }^{1}$

Makoto Watanabe ${ }^{2}$ 
${ }^{1}$ University of Munich, Germany

${ }^{2}$ Vrije Universiteit Amsterdam, Tinbergen Institute

Tinbergen Institute is the graduate school and research institute in economics of Erasmus University Rotterdam, the University of Amsterdam and VU University Amsterdam.

Contact: discussionpapers@tinbergen.nl

More TI discussion papers can be downloaded at http://www.tinbergen.nl

Tinbergen Institute has two locations:

Tinbergen Institute Amsterdam

Gustav Mahlerplein 117

1082 MS Amsterdam

The Netherlands

Tel.: $+31(0) 205984580$

Tinbergen Institute Rotterdam

Burg. Oudlaan 50

3062 PA Rotterdam

The Netherlands

Tel.: +31(0)10408 8900 


\title{
Intermediation Services and Search Frictions*
}

\author{
Christian Holzner ${ }^{\dagger} \quad$ Makoto Watanabe ${ }^{\ddagger}$
}

April 25, 2017

\begin{abstract}
In many countries Public Employment Agencies (PEA) offer intermediation services to help as many people as possible to find work by bringing together supply and demand. Using a unique vacancy-level data-set on the number of applicants, we find positive effects of the intermediation services on mitigating search frictions. In particular, we show that applications coming via the PEA are more evenly distributed across vacancies than the applications coming via other search channels. This holds for the total number of applicants as well as the suitable number of applicants. Our results suggest that the market operated by the PEA attains more coordinated job applications compared to other search channels.
\end{abstract}

Keywords: Intermediation, Public Employment Agency

JEL: J6

\footnotetext{
${ }^{*}$ We are grateful to Bernd Fitzenberger and Hermann Gartner for their comments and suggestions. The survey data used are confidential but not exclusive. Access to the data is provided by the Research Data Centre of the German Federal Employment Agency. For details, see fdz.iab.de. To facilitate replication the Stata do-files are available upon request.

${ }^{\dagger}$ Ifo Institute for Economic Research at the University of Munich. Address: Poschingerstrasse 5, 81679 Munich, Germany. Email: holzner@ifo.de. Tel.: +49-899224-1278, Fax: +49-899224-1604.

${ }^{\ddagger}$ Department of Economics, FEWEB, VU Amsterdam and Tinbergen Institute. Address: Department of Economics, VU Amsterdam, De Boelelaan 1105, 1081 HV Amsterdam, The Netherlands. Email: makoto.wtnb@gmail.com. Tel.: +31-20598-6030. Fax: +31-20598-9870.
} 


\section{Introduction}

Almost all industrialized countries have large publicly funded intermediation services in the labor market, the Public Employment Agencies (PEA). Public Employment Agencies are responsible for the administration of unemployment benefits, for improving the employability of unemployed, and for providing intermediation services to help as many people as possible to find work by bringing together supply and demand. While the first two responsibilities have received much attention in the economics literature, ${ }^{1}$ very little is known about the intermediation services provided by the PEA and their effect on the labor market.

In fact, the PEA realizes that trade in the labor market is a nontrivial economic activity - job search is costly and time-consuming, and job applications are uncoordinated. The PEA, therefore, offers an online platform where workers can search and apply for vacancies and firms can post ads electronically. More importantly, the PEA encourages unemployed workers to search more and introduces them to new vacancies, which they would not have considered otherwise. It also supports employers in finding suitable personnel, especially those who have difficult-to-fill vacancies. All these measures are supposed to reduce search frictions, where due to the lack of coordination some vacancies are left with few (suitable) applicants and others with many. Indeed, uncoordinated applications are considered a major obstacle to the smooth functioning of the labor market (see, for example, Petrongolo and Pissarides, 2001).

We investigate whether the intermediation services provided by the PEA reduce search frictions. To do so we use the German Job Vacancy Survey, a representative establishment data-set collected by the Federal Employment Agency. This is the perfect data-set for our purpose since it contains numerous questions regarding the recruitment process. Most importantly the survey contains information on how many applicants and how many suitable applicants a registered vacancy received via the PEA and through other search channels.

Our findings are positive about the effect of the intermediation services. First of all, we find that applicants coming from the PEA are more evenly spread than applicants coming from the private market. This holds for the total number of applicants as well as for the suitable number of applicants. With a more even distribution, there are fewer vacancies with few (suitable) applicants and fewer vacancies with a lot of (suitable) applicants.

To take into account differences across sub-markets for different types of vacancies (occupations, industries, and other vacancy and firm characteristics), we also run OLS regressions explaining the number of (suitable) applicants separately for those coming via the PEA and the private market using the job- and firm- characteristics as explanatory variables. This allows us to decompose the number of (suit-

\footnotetext{
${ }^{1}$ Early studies on the effects of unemployment benefits and unemployment duration are Narendaranathan et al. (1985), Katz and Meyer (1990), Hunt (1995), and Nickell and Layard (1999). More recent studies are Lalive and Zweimüller (2004), Lalive (2007), and Lalive et al. (2015). The effect of sanctions is among others studied by Van den Berg et al. (2004), Abbring et al. (2005), Lalive et al. (2005), and Svarer (2011). Couch (1992), Heckman et al. (1999), Lechner and Wunsch (2009), and Lechner et al. (2011) study the effects of training programs.
} 
able) applicants into an explained and an unexplained part given the vacancy and firm characteristics observed in the German Job Vacancy Survey. By doing so we can investigate which part of the variation in the number of (suitable) applicants can be attributed to the respective sub-markets (explained part) and which part can be attributed to the underlying random application process (unexplained part). Comparing the distributions of the residuals (unexplained part) for the number of applicants coming from the PEA and the private market, we confirm our finding that the PEA distributes applicants especially suitable applicants - more evenly than the private market.

The search literature refers to the underlying random application process as coordination frictions (see, for example, Burdett et al., 2001; Shimer, 2005; Albrecht et al., 2006; and Galenianos and Kircher, 2009). This interpretation is based on the common assumption that job seekers observe the type of sub-market a vacancy belongs to but they do not know to which vacancies - of the same sub-market - other job seekers apply. Hence, our finding suggests that coordination frictions are less severe in the market operated by the PEA compared to the private market.

It is worth mentioning that the OLS regression results are interesting in themselves. The job- and firm-characteristics, which matter for the private market, play either no or the reverse role in the PEA. This indicates that the PEA guides its job seekers either irrespective of or contrary to the characteristics which attract workers in the private market. By doing so it helps vacancies, which find it hard to attract (suitable) applicants in the private market, to increase their number of (suitable) applicants.

Finally, we investigate differences in the application behavior of non-employed workers in more details. Using the German Socio Eoconomic Panel (GSOEP), we find that those, who use the PEA as search channel, more often use other search channels compared to those, who do not use the PEA. The increase in search effort is evenly spread among all other search channels. The last result rules out that the coordination reducing effect attributed to the PEA might in reality be driven by another search channel.

The finding that the PEA encourages search also via other search channels is in contrast to the pioneering theoretical work of the PEA by Pissarides (1979), who hypothesized that the PEA would crowd out private search incentives of individuals. The economic literature has so far been silent on this issue. Blau and Robins (1990) for the US, Osberg (1993) for Canada, Gregg and Wadsworth (1996) for the UK, and Addison and Protugal (2002) for Portugal, who analyze the effect of the PEA search channel on the job finding rate, did not intend to separate the effect on individual search effort (which together with the job contact rate determines the job finding rate). Fugère et al. (2009) instead study the effect of the PEA on the job finding rate using a structural partial search equilibrium model which assumes that the PEA crowds out private search incentives.

The remainder of the paper is organized as follows. In Section 2, we explain how the PEA works in Germany. In Section 3 we describe the data-sets. In Section 4, we present our main findings. Section 5 concludes. Some omitted tables are collected in the Appendix. 


\section{The Public Employment Agency}

In 2015 the PEA in Germany had an overall budget of 31.5 Billion Euros. Around one fourth of the total budget, i.e., 7.93 Billion Euros, was spent on administration including the wage costs for the roughly 90,000 workers employed at the PEA. The German government therefore spends around 0.3\% of German GDP on the administration cost of the PEA. A significant fraction of employees deal with the administration of unemployment benefits. Still, more than half of the the PEA's employees work in the intermediation to help workers and vacancies to find a good match. This section explains what kind of intermediation services are provided by the PEA.

If a worker becomes unemployed, she registers with the PEA and is assigned to a case manager. The case manager will interview the person. A worker, who has some deficits, will be offered training. The majority of unemployed do not get training, they are only taught how to use the online search platform (https://jobboerse.arbeitsagentur.de). Job seekers can upload their curriculum vitae to the platform, post job wanted adds, and search actively for vacancies posted. All unemployed workers, who receive benefits, are required to register and to sign an agreement that determines the individual specific search effort, which they have to fulfill. The case manager has access to an individual worker's platform account and can observe where the worker applied and whether the worker has been invited for a job interview. The case manager will propose certain jobs to the worker, if the worker's qualifications match the job description. With their experience case managers can encourage search, broaden the view of applicants, and suggest jobs, which workers would not have considered on their own.

On top of coaching unemployed workers, the PEA offers recruiting assistance to vacancies. The registration of vacancies at the online platform is voluntary. Firms, which post a vacancy on the platform, can search actively for registered workers and decide whether to make the vacancy available for recommendations by case managers. They can also ask their contact person at the PEA to propose workers. They can then contact these workers via the internal mailing system provided by the platform. The contact person is asked to recommend at least one worker within 48 hour. The vacancy can also set a maximum for the number of applicants it wants to receive from the PEA (in order to limit screening costs). In case the vacancy asks for recruiting assistance the contact person can view the platform account of the specific vacancy and manage the number of recommendations made by case managers accordingly. The contact person can also provide additional information about other services (e.g. subsidies) provided by the PEA. This type of recruiting assistance does not only lower recruitment costs, but also enables firms to minimize the risk of not receiving any applicant.

In the years 2005 to 2008, 55.7\% of all vacancies in Germany were advertised in news papers, $48.3 \%$ used the services provided by the PEA (12.6\% only at the agency, $12.7 \%$ only on the PEAonline platform and $23.0 \%$ both), and $45.3 \%$ of all vacancies were posted on the internet (excluding the online-platform of the PEA). The PEA is thus the second most used search channel by firm to contact workers. The PEA is also the second most important search channel of non-employed workers. In the years 2005 to $2007,73.7 \%$ of all non-employed individuals, who actively searched in the last four 
weeks, search through job ads in news papers, $70.9 \%$ used the PEA as search channel, $64.2 \%$ searched via their personal network, $50.5 \%$ searched on the internet (possibly including the online-platform of the PEA), and $25.5 \%$ send speculative applications to firms.

\section{Data Sets}

The following two data-sets are used in the analysis, the German Job Vacancy Survey to gain information about how the PEA influences firms' job search process and the German Socio Economic Panel (GSOEP) to gain information on how the PEA influences workers' job search behavior.

\section{German Job Vacancy Survey}

The German Job Vacancy Survey is collected by the Federal Employment Agency in German. ${ }^{2}$ It is based on a representative sample of establishments, which is newly sampled each year. The yearly survey started in 1989 and was initially conducted to provide an estimate of the total number of vacancies in Germany relative to the number of vacancies registered with the PEA.

The survey includes establishment level data on the number of employees, number of vacancies, hires and quits in the last 12 months, and information on the industry and region of the firm. The economic conditions of a firm can be proxied by binary indicator variables for "low sales", "financial constraints", and "not enough suitable employees". It also contains a number of questions concerning the last case of a successfully filled vacancy. In this part of the survey firms were asked which search channels they used and through which channel they hired. The survey also provides information on the number of applicants, the number of suitable applicants, the qualification and experience level required for the job, information on job characteristics like occupation, permanent/temporary, full-/part-time, and weekend-work required.

For the main analysis on whether the PEA reduces coordination frictions we can use the information on the number of applicants and the number of suitable applicants in total and the number of applicants and the number of suitable applicants sent by the PEA. ${ }^{3}$ This information is available for registered vacancies in the years 2005 to 2008 . We can therefore compare the distribution of (suitable) applicants sent by the PEA and the distribution of (suitable) applicants coming through the private market for the same set of vacancies.

\footnotetext{
${ }^{2}$ The data used in this article were made available to us by the Research Data Centre of the German Federal Employment Agency at the Institute for Employment Research (IAB), Nuremberg.

${ }^{3}$ A firm will only label a worker as being "sent by the PEA", if it got notice that the PEA was involved. This is clearly the case, if the vacancy asked for recruiting assistance and was recommended the applicants by its contact person. The firm could also learn it from the applicant. In Germany, it is common practice that one states in the first sentence of the application letter, where one learned about the open position. If the vacancy is registered with the PEA, the firm signals that it is willing to employ unemployed workers. There is therefore no incentive for job seekers to conceal that they learned about the open position through the PEA. In this case the worker could have found the vacancy via the online-platform of the PEA, or her case manager recommended the vacancy to her. For data security reasons the data-set cannot be linked to the information on the online platform. So there is no information available on the kind of intermediation services, which were used during the recruitment process.
} 
Since our data contains only vacancies, which successfully hired a worker, each vacancy has at least one applicant and at least one suitable applicant. The distributions of (suitable) applicants are therefore conditional on firms having been successful. The German Job Vacancy Survey also questions vacancies, which were not successful in hiring a suitable applicant. According to Gartner and Holzner (2015) the unsuccessful vacancies amount to 4.6 percent of all posted vacancies. Since the respective firms where not asked about the number of (suitable) applicants, we do not know whether they have been unsuccessful because they had no suitable applicant, or because their suitable applicants decided to take up other offers. We also cannot differentiate between the number of (suitable) applicants coming via the PEA and the private market.

Two samples are used in the analysis, the full sample and a subsample, which only includes vacancies, which were successful in filling their position before the intended starting data of the employment contract. The subsample is referred to as the restricted sample. The restricted sample excludes cases in which a firm might rethink its search strategy after having failed to find a worker within the expected time period. These cases are excluded to rule out reverse causality, i.e., the cases where firms, which initially did not use the PEA search channel, decided to do so after having failed to find a suitable worker in time.

\section{German Socio Economic Panel}

The German Socio Economic Panel (GSOEP) is used to complement the picture and provide an inside into which search channels are used by workers. The GSOEP is a longitudinal survey of German households. It started in 1984 and is conducted on the annual basis ever since. ${ }^{4}$ The GSOEP is the largest and most comprehensive household panel in Germany, which compared to the administrative data provided by the Federal Employment Agency includes not only the job search information of unemployed workers registered with the PEA but also of other non-employed workers, who want to find a job.

The main information used is the information on the search behavior of non-employed individuals. For the years 2005 to 2007 non-employed individuals were asked whether they search actively for a job in the last four weeks. We select those non-employed workers, who send at least one application and who are below the age of $60 .{ }^{5}$ For them the GSOEP provides the information on the search channels they used (PEA, job ads, internet, personal network, speculative application) and a host of personal characteristics including whether they are registered as unemployed with the PEA.

\footnotetext{
${ }^{4}$ The data used in this article were made available to us by the German Socio-Economic Panel Study (SOEP) at the German Institute for Economic Research (DIW), Berlin.

${ }^{5}$ Workers above the age of 60 are excluded, since they can receive unemployment benefits without actively searching for a job.
} 


\section{Main Results}

The intermediation services provided by the PEA aim at reducing search frictions, where applications due to the lack of coordination - are unevenly distributed across vacancies. The guidance of applications of unemployed job seekers and the support of difficult-to-fill vacancies provided by the PEA are supposed to result in a more even distribution of applications across vacancies compared to the private market. To empirically test this hypothesis, this paper compares the PEA-induced distribution of job applicants with the distribution of job applicants coming through private market search channels. If our hypothesis holds, then the number of applicants sent by the PEA should be more evenly distributed among vacancies than the number of applicants that the same vacancies receive through the private market.

Since we observe for all registered vacancies the number of (suitable) applicants coming from the PEA and the private market, we can calculate the inequality measures for the number of (suitable) applicants coming from the PEA and the private market based on the same set of vacancies. In other words, the effect of the PEA on the distribution of (suitable) applicants is identified by the variation within vacancies.

\subsection{Comparing the Distributions of (Suitable) Applicants}

We will first analyze whether the absolute number of (suitable) applicants coming from the PEA is more evenly distributed than the absolute number of (suitable) applicants coming from the private market. Since the difference in the distributions can be driven by differences across different sub-markets for vacancies of different occupations, industries or with certain vacancy characteristics, we will in a second step analyze whether our finding also holds once we consider the residuals of multivariate regressions.

To analyze our main hypothesis we use three commonly used inequality measures to characterize the (in)equality of the distribution of applicants; the Gini coefficient, the variance of logs, and the coefficient of variation. ${ }^{6}$

\section{Absolute Number of (Suitable) Applicants}

Table 1 shows the Gini coefficient, the variance of logs, and the coefficient of variation for the number of applicants and the number of suitable applicants using the full sample and the restricted sample. The restricted sample excludes vacancies, which failed to find a worker within the expected time period. It is therefore unlikely that it suffers from reverse causality and thus more reliable. Column (3) presents the difference between the Gini coefficients in column (1) to column (2) and the ratios of the variance of logs, and the coefficient of variation in column (1) to column (2), respectively. ${ }^{7}$

\footnotetext{
${ }^{6}$ Since the variance of logs normally drops observations with a value of zero, we decided to use all observations and to add 1 to all values before calculating the respective inequality measure.

The three measures differ in their sensitivity towards changes in the mean or changes in the tails (see e.g. Bendel et al., 1989; Cowell and Flachaire, 2007). The coefficient of variation and the Gini coefficient are more sensitive to shifts in the mean compared to the variance of logs. The coefficient of variation and the variance of logs are more sensitive to changes in the tails of the distribution compared to the Gini coefficient.

${ }^{7}$ The significance of the difference in the Gini coefficients is based on a t-test, the significance of the ratio of the variance of logs on a variance-ratio-test. The coefficient of variation $(C V)$ is calculated based on the assumption that the
} 
Table 1: Inequality measures for the number of (suitable) applicants coming via the PEA and the private market

\begin{tabular}{cccc}
\hline \hline & Private Market & PEA & Difference / Ratio \\
& $(1)$ & Gini coefficients & \\
\hline \hline & & & \\
full sample & & 0.6257 & $0.1117^{* *}$ \\
number of applicants & 0.7374 & $(0.0524)$ & $0.1574^{* * *}$ \\
number of suitable applicants & $(0.0376)$ & 0.4726 & \\
& 0.6300 & $(0.0293)$ & $0.1579^{* * *}$ \\
restricted sample & $(0.0416)$ & & $0.1038^{* * *}$ \\
number of applicants & & 0.5973 & \\
number of suitable applicants & 0.7552 & $0.0411)$ & 0.4873 \\
& $(0.0496)$ & $(0.0432)$ & \\
\end{tabular}

\begin{tabular}{|c|c|c|c|}
\hline & \multicolumn{3}{|c|}{ Variance of logs } \\
\hline \multicolumn{4}{|l|}{ full sample } \\
\hline number of applicants & 2.0606 & 1.2413 & $1.6600^{* * *}$ \\
\hline number of suitable applicants & 0.9092 & 0.5778 & $1.5737^{* * *}$ \\
\hline \multicolumn{4}{|l|}{ restricted sample } \\
\hline number of applicants & 2.0835 & 1.2081 & $1.7247 * * *$ \\
\hline \multirow[t]{2}{*}{ number of suitable applicants } & 0.8052 & 0.5992 & $1.3437^{* * *}$ \\
\hline & \multicolumn{3}{|c|}{ Coefficient of variation } \\
\hline \multicolumn{4}{|l|}{ full sample } \\
\hline number of applicants & 2.6173 & 1.5684 & $1.6687^{* * *}$ \\
\hline number of suitable applicants & 1.2175 & 0.8843 & $1.3768^{* * *}$ \\
\hline \multicolumn{4}{|l|}{ restricted sample } \\
\hline number of applicants & 2.6519 & 1.5320 & $1.7310^{* * *}$ \\
\hline number of suitable applicants & 1.1123 & 0.9059 & $1.2277^{* * *}$ \\
\hline
\end{tabular}

Source: German Job Vacancy Survey 2005-2008.

The full sample contains 5547 observations for the number of applicants and 5058 observations for the number of suitable applicants. For the restricted sample the numbers are respectively given by 3122 and 2855 . All measures are calculated using sampling weights. The t-test $\left(\mathrm{H}_{0}:\right.$ Difference $\left.=0\right)$ is based on the standard error, which are provided in the parentheses. Variance-ratio-test $\left(\mathrm{H}_{0}:\right.$ Ratio $\left.=1\right)$ is based on the F-statistic with the degree of freedom given by the respective number of observations minus 1 . *** indicates $p<0.01 ;{ }^{* *} p<0.05 ;{ }^{*} p<0.1$.

The Gini coefficient, the variance of logs, and the coefficient of variation for the number of applicants sent by the PEA are smaller than the respective measures for the number of applicants that apply through private market search channels. All three inequality measures therefore show that the number of applicants coming from the PEA are more evenly distributed than the number of applicants coming from the private market. The differences in the Gini coefficients are statistically significant at a $5 \%$ respective variable is log-normally distributed, i.e., $C V(x)=\sqrt{e^{\operatorname{Var}(\ln (x))}-1}$. This allows us to infer the significance of the ratio of CVs from the variance ratio test of the variance of logs. 
level and the ratios for the variance of logs and the coefficient of variation are statistically different from 1 at a $1 \%$ level. This holds for the full and the restricted sample. Table 1 also presents the results based on the number of suitable applicants. The respective differences and ratios are slightly smaller but equally significant. This is reassuring, since Holzner and Watanabe (2017) show - using the same data set - that the fraction of suitable applicants coming from the PEA is significantly lower than the respective fraction of suitable workers, who applied through the private market.

Our result turns out to be very robust. It holds for the majority of subgroups of vacancies irrespective of whether we take the full or the restricted sample or focus on the number of applicants or number of suitable applicants as shown in Tables A.2 and A.3 in the Appendix. Only sub-markets for part-time jobs, jobs requiring weekend-work and jobs offered by firms between 200 and 500 employees are in some cases insignificant. Running the analysis for separate subgroups is a first step to account for the fact that different types of vacancies are part of different sub-markets.

\section{Residual Number of (Suitable) Applicants}

Considering the absolute number of (suitable) applicants across all types of vacancies implicitly assumes that all vacancies are part of one labor market. In reality, however, markets are segmented along occupations, industries, as well as vacancy and firm characteristics. By decomposing the number of (suitable) applicants into an explained and an unexplained part we can investigate which part of the variation in the number of (suitable) applicants can be attributed to the respective sub-markets (explained part) and which part can be attributed to the underlying random application process (unexplained part). The search literature interprets the underlying random application process as coordination frictions. This interpretation is based on the common assumption made in this literature that job seekers observe the type of sub-market a vacancy belongs to but they do not know to which vacancies - of the same sub-market - other job seekers apply (see, for example, Burdett et al., 2001; Shimer, 2005; Albrecht et al., 2006; and Galenianos and Kircher, 2009).

The decomposition will again be done separately for the number of (suitable) applicants coming from the PEA and the private market. Table 2 presents the respective results for the number of applicants and Table 3 for the number of suitable applicants. The results for the number of (suitable) applicants coming via the PEA are presented in columns (1) and (3) and via the private market in columns (2) and (4). Columns (1) and (2) present the results for the full sample and columns (3) and (4) for the restricted sample.

The regression results are interesting in themselves. While jobs requiring low qualifications receive fewer applicants from the private market, no such effect can be found for applicants sent by the PEA. A similar phenomena can be observed if the job requires a high qualification, occupation specific experience, weekend-work, and if the job is permanent or posted by a large firm. All these factors are positively correlated with the number of applicants coming through the private market, but the respective coefficients for the number of applicants sent by the PEA are either insignificant or have the 
Table 2: Number of applicants through the PEA and the private market

\begin{tabular}{|c|c|c|c|c|}
\hline & \multicolumn{4}{|c|}{ OLS-Regressions } \\
\hline & \multicolumn{2}{|c|}{ full sample } & \multicolumn{2}{|c|}{ restricted sample } \\
\hline & \multicolumn{4}{|c|}{ Log of the number of applicants coming via the } \\
\hline & PEA & private market & PEA & private market \\
\hline & (1) & $(2)$ & $(3)$ & $(4)$ \\
\hline low qualification & $\begin{array}{l}-0.0165 \\
(0.0625)\end{array}$ & $\begin{array}{c}-0.3784^{* * *} \\
(0.0772)\end{array}$ & $\begin{array}{l}-0.1230 \\
(0.0873)\end{array}$ & $\begin{array}{c}-0.4048^{* * *} \\
(0.1091)\end{array}$ \\
\hline high qualification & $\begin{array}{c}-0.1554^{* * *} \\
(0.0600)\end{array}$ & $\begin{array}{c}0.3271 * * * \\
(0.0773)\end{array}$ & $\begin{array}{l}-0.1177 \\
(0.0790)\end{array}$ & $\begin{array}{c}0.2673^{* *} \\
(0.1048)\end{array}$ \\
\hline occupation specific experience & $\begin{array}{c}0.0107 \\
(0.0322)\end{array}$ & $\begin{array}{c}0.1207 * * * \\
(0.0410)\end{array}$ & $\begin{array}{c}0.0350 \\
(0.0434)\end{array}$ & $\begin{array}{c}0.1567 * * * \\
(0.0578)\end{array}$ \\
\hline permanent & $\begin{array}{c}0.0416 \\
(0.0332)\end{array}$ & $\begin{array}{c}0.3073^{* * *} * \\
(0.0421)\end{array}$ & $\begin{array}{c}0.0650 \\
(0.0465)\end{array}$ & $\begin{array}{c}0.3561 * * * \\
(0.0607)\end{array}$ \\
\hline full-time & $\begin{array}{c}0.1367^{* * *} \\
(0.0437)\end{array}$ & $\begin{array}{c}0.0739 \\
(0.0593)\end{array}$ & $\begin{array}{c}0.1177^{* *} \\
(0.0562)\end{array}$ & $\begin{array}{c}0.0322 \\
(0.0782)\end{array}$ \\
\hline weekend-work & $\begin{array}{c}0.0144 \\
(0.0504)\end{array}$ & $\begin{array}{c}0.1518^{* *} \\
(0.0658)\end{array}$ & $\begin{array}{c}0.0375 \\
(0.0704)\end{array}$ & $\begin{array}{c}0.2244^{* *} \\
(0.0911)\end{array}$ \\
\hline firm size (log) & $\begin{array}{c}-0.0303^{* * *} \\
(0.0117)\end{array}$ & $\begin{array}{c}0.1482^{* * *} \\
(0.0151)\end{array}$ & $\begin{array}{l}-0.0080 \\
(0.0157)\end{array}$ & $\begin{array}{c}0.1301 * * * \\
(0.0213)\end{array}$ \\
\hline "financial constraints" & $\begin{array}{l}0.0897^{*} \\
(0.0526)\end{array}$ & $\begin{array}{c}0.0014 \\
(0.0673)\end{array}$ & $\begin{array}{c}0.0732 \\
(0.0719)\end{array}$ & $\begin{array}{c}0.0176 \\
(0.0964)\end{array}$ \\
\hline "low sales" & $\begin{array}{c}0.0098 \\
(0.0431)\end{array}$ & $\begin{array}{l}-0.0268 \\
(0.0517)\end{array}$ & $\begin{array}{l}0.1019^{*} \\
(0.0615)\end{array}$ & $\begin{array}{l}-0.1123 \\
(0.0754)\end{array}$ \\
\hline "not enough suitable employees" & $\begin{array}{c}-0.1300^{* *} \\
(0.0515)\end{array}$ & $\begin{array}{c}0.0572 \\
(0.0576)\end{array}$ & $\begin{array}{l}-0.1273 \\
(0.0833)\end{array}$ & $\begin{array}{l}0.0175 \\
(0.0947)\end{array}$ \\
\hline \multirow{2}{*}{$\begin{array}{l}\text { year-, region-, occup.-, ind.-FE } \\
\text { (year x region)-FE }\end{array}$} & yes & yes & yes & yes \\
\hline & yes & yes & yes & yes \\
\hline $\mathrm{R}^{2}$ & 0.1882 & 0.2868 & 0.2195 & 0.3326 \\
\hline $\mathrm{N}$ & 4,287 & 4,287 & 2,491 & 2,491 \\
\hline
\end{tabular}

Source: German Job Vacancy Survey 2005-2008.

Robust standard errors in brackets. ${ }^{* * *}$ indicates $p<0.01 ;{ }^{* *} p<0.05 ;{ }^{*} p<0.1$.

opposite sign. ${ }^{8}$ The cases, where job or firm characteristics are insignificant in explaining the number of applicants coming from the PEA but significant in explaining the number of applicants coming from the private market, suggest that the PEA distributes its applicants irrespective of these characteristics. The cases where the coefficients have the opposite sign suggest that the PEA, to some extent, gives priority to those vacancies that find it more difficult to attract workers via the private market.

The picture for the number of suitable applicants is similar. There are only a few differences. Temporary jobs receive significantly fewer suitable applicants via the PEA (and significantly more via the private market), while its impact on the number of applicants coming via the PEA was insignificant. This indicates that the PEA compensates the disadvantage that temporary jobs have in the private market in attracting suitable applicants. While such a compensating effect could also be observed for small firms in case of the number of applicants, the results in Table 3 suggest that this does not hold for the number of suitable applicants.

\footnotetext{
${ }^{8}$ Only full-time jobs receive more applicants from the PEA than from the private market.
} 
Table 3: Number of suitable applicants through the PEA and the private market

\begin{tabular}{|c|c|c|c|c|}
\hline & \multicolumn{4}{|c|}{ OLS-Regressions } \\
\hline & \multicolumn{2}{|c|}{ full sample } & \multicolumn{2}{|c|}{ restricted sample } \\
\hline & \multicolumn{4}{|c|}{ Log of the number of suitable applicants coming via the } \\
\hline & PEA & private market & PEA & private market \\
\hline & $(1)$ & $(2)$ & $(3)$ & $(4)$ \\
\hline low qualification & $\begin{array}{c}0.0554 \\
(0.0442)\end{array}$ & $\begin{array}{c}-0.2239^{* * * *} \\
(0.0517)\end{array}$ & $\begin{array}{l}0.0200 \\
(0.0587)\end{array}$ & $\begin{array}{c}-0.2250^{* * * *} \\
(0.0733)\end{array}$ \\
\hline high qualification & $\begin{array}{r}-0.0857^{*} \\
(0.0453)\end{array}$ & $\begin{array}{c}0.1685^{* * *} \\
(0.0552)\end{array}$ & $\begin{array}{c}0.0100 \\
(0.0621)\end{array}$ & $\begin{array}{c}0.1913^{* *} \\
(0.0770)\end{array}$ \\
\hline occupation specific experience & $\begin{array}{l}-0.0076 \\
(0.0237)\end{array}$ & $\begin{array}{l}-0.0163 \\
(0.0281)\end{array}$ & $\begin{array}{l}-0.0165 \\
(0.0326)\end{array}$ & $\begin{array}{c}0.0309 \\
(0.0404)\end{array}$ \\
\hline permanent & $\begin{array}{c}-0.0502^{* *} \\
(0.0246)\end{array}$ & $\begin{array}{c}0.1683^{* * *} * \\
(0.0291)\end{array}$ & $\begin{array}{c}-0.0647^{*} \\
(0.0357)\end{array}$ & $\begin{array}{c}0.2064^{* * *} * \\
(0.0432)\end{array}$ \\
\hline full-time & $\begin{array}{c}0.0369 \\
(0.0336)\end{array}$ & $\begin{array}{l}-0.0130 \\
(0.0412)\end{array}$ & $\begin{array}{c}0.0081 \\
(0.0451)\end{array}$ & $\begin{array}{l}-0.0206 \\
(0.0560)\end{array}$ \\
\hline weekend-work & $\begin{array}{l}-0.0160 \\
(0.0365)\end{array}$ & $\begin{array}{l}0.0951^{* *} \\
(0.0447)\end{array}$ & $\begin{array}{l}-0.0364 \\
(0.0506)\end{array}$ & $\begin{array}{l}0.1242^{* *} \\
(0.0632)\end{array}$ \\
\hline firm size $(\log )$ & $\begin{array}{c}0.0195^{* *} * \\
(0.0088)\end{array}$ & $\begin{array}{c}0.1101^{* * *} \\
(0.0108)\end{array}$ & $\begin{array}{c}0.0272^{* *} \\
(0.0122)\end{array}$ & $\begin{array}{c}0.1104^{* * *} \\
(0.0153)\end{array}$ \\
\hline "financial constraints" & $\begin{array}{l}0.0726^{*} \\
(0.0408)\end{array}$ & $\begin{array}{c}0.0279 \\
(0.0492)\end{array}$ & $\begin{array}{c}0.0180 \\
(0.0550)\end{array}$ & $\begin{array}{c}0.0168 \\
(0.0712)\end{array}$ \\
\hline "low sales" & $\begin{array}{c}0.0154 \\
(0.0308)\end{array}$ & $\begin{array}{c}0.0148 \\
(0.0349)\end{array}$ & $\begin{array}{c}0.0301 \\
(0.0449)\end{array}$ & $\begin{array}{l}-0.0576 \\
(0.0515)\end{array}$ \\
\hline "not enough suitable employees" & $\begin{array}{c}-0.2295^{* * *} \\
(0.0321)\end{array}$ & $\begin{array}{l}-0.0317 \\
(0.0371)\end{array}$ & $\begin{array}{c}-0.2682^{* * * *} \\
(0.0534)\end{array}$ & $\begin{array}{l}-0.0662 \\
(0.0627)\end{array}$ \\
\hline \multirow{2}{*}{$\begin{array}{l}\text { year-, region-, occup.-, ind.-FE } \\
\text { (year x region)-FE }\end{array}$} & yes & yes & yes & yes \\
\hline & yes & yes & yes & yes \\
\hline $\mathrm{R}^{2}$ & 0.2203 & 0.2517 & 0.2691 & 0.3061 \\
\hline $\mathrm{N}$ & 4,179 & 4,179 & 2,407 & 2,407 \\
\hline
\end{tabular}

Source: German Job Vacancy Survey 2005-2008.

Robust standard errors in brackets. ${ }^{* * *}$ indicates $p<0.01 ;{ }^{* *} p<0.05 ;{ }^{*} p<0.1$.

For the following decomposition it is important to observe that job and firm characteristics seem to matter a lot in explaining the number of (suitable) applicants coming via the private market but not in explaining the number of (suitable) workers coming via the PEA. This follows from the fact that the $\mathrm{R}^{2}$ is between 28.7 to 33.3 (25.2 to 30.6 ) for regressions explaining the number of (suitable) applicants coming via the private market but only 18.8 to 22.0 (22.0 to 26.9) for the respective regressions explaining the number of (suitable) applicants coming from the PEA. The lower explanatory power of the control variables leads directly to a higher variance in the unexplained (residual) part. ${ }^{9}$

The inequality measures calculated based on the OLS residuals are shown in Table $4 .{ }^{10}$ As expected -

\footnotetext{
${ }^{9}$ The lower explanatory power in the regressions for the number of (suitable) applicants coming from the PEA compared to the the private market also implies that firms find it harder to predict the number of workers coming from the PEA compared to the private market. This might be one reason, why not all firms find it attractive to register their vacancy with the PEA. For a more general treatment of why some firms might register their vacancy while others do not see Holzner and Watanabe (2017).

${ }^{10}$ Since the dependent variable in the OLS regressions is the log of the number of (suitable) applicants, the residuals of the OLS regressions are the log of the unexplained part of the number of (suitable) applicants. We can therefore straightforwardly obtain the inequality measure variance of logs by calculating the variance of the residuals. Given
} 
Table 4: Inequality measures for the residuals of number of (suitable) applicants coming via the PEA and the private market

\begin{tabular}{|c|c|c|c|}
\hline & $\begin{array}{c}\text { Private Market } \\
\text { (1) }\end{array}$ & $\begin{array}{l}\text { PEA } \\
(2)\end{array}$ & $\begin{array}{c}\text { Difference / Ratio } \\
\text { (3) }\end{array}$ \\
\hline & \multicolumn{3}{|c|}{ Gini coefficients } \\
\hline \multicolumn{4}{|l|}{ full sample } \\
\hline number of applicants & $\begin{array}{c}0.0574 \\
(0.0034)\end{array}$ & $\begin{array}{c}0.0487 \\
(0.0029)\end{array}$ & $0.0087 * *$ \\
\hline number of suitable applicants & $\begin{array}{c}0.0471 \\
(0.0030)\end{array}$ & $\begin{array}{c}0.0337 \\
(0.0024)\end{array}$ & $0.0134^{* * *}$ \\
\hline \multicolumn{4}{|l|}{ restricted sample } \\
\hline number of applicants & $\begin{array}{c}0.0649 \\
(0.0059)\end{array}$ & $\begin{array}{c}0.0622 \\
(0.0060)\end{array}$ & 0.0027 \\
\hline number of suitable applicants & $\begin{array}{c}0.0541 \\
(0.0059)\end{array}$ & $\begin{array}{c}0.0426 \\
(0.0056)\end{array}$ & $0.0115^{*}$ \\
\hline
\end{tabular}

Variance of logs

$\begin{array}{llll}\text { full sample } & & & \\ \quad \text { number of applicants } & 0.0115 & 0.0088 & 1.3116^{* * *} \\ \text { number of suitable applicants } & 0.0081 & 0.0042 & 1.9178^{* * *} \\ \text { restricted sample } & & & \\ \quad \text { number of applicants } & 0.0148 & 0.0139 & 1.0665 \\ \quad \text { number of suitable applicants } & 0.0113 & 0.0071 & 1.5861^{* * *}\end{array}$

Coefficient of variation

$\begin{array}{llll}\text { full sample } & & \\ \quad \text { number of applicants } & 0.1076 & 0.0939 & 1.1461^{* * *} \\ \text { number of suitable applicants } & 0.0904 & 0.0652 & 1.3862^{* * *} \\ \quad & & 1.0330 \\ \begin{array}{l}\text { restricted sample } \\ \text { number of applicants }\end{array} & 0.1220 & 0.1181 & 1.2607^{* * *} \\ \quad \text { number of suitable applicants } & 0.1064 & 0.0844 & \end{array}$

Source: German Job Vacancy Survey 2005-2008.

The full sample contains 3974 observations for the number of applicants and 3653 observations for the number of suitable applicants. For the restricted sample the numbers are respectively given by 2283 and 2092 . All measures are calculated using sampling weights. The t-test $\left(\mathrm{H}_{0}\right.$ : Difference $\left.=0\right)$ is based on the standard error, which are provided in the parentheses. Variance-ratio-test $\left(\mathrm{H}_{0}\right.$ : Ratio $\left.=1\right)$ is based on the F-statistic with the degree of freedom given by the respective number of observations minus 1 . *** indicates $p<0.01 ; * * p<0.05$; ${ }^{*} p<0.1$.

given the lower explanatory power of the OLS regressions for the number of (suitable) applicants coming from the PEA compared to the private market - the results based on the residuals of the OLS regression are less pronounced. The results for the full sample still strongly support our hypothesis but the results the interpretation that the residuals are the $\log$ of the unexplained part of the number of (suitable) applicants, we can transform the residuals into the unexplained part of the number of (suitable) applicants by taking the exponential operator. Since the OLS regressions force the mean of the residuals to be equal to zero, the respective means of the unexplained part of the number of (suitable) applicants is always equal to one. The respective coefficient of variation is therefore given by the variance of the transformed residuals. The Gini coefficients are also calculated based on the transformed residuals. 
on the restricted sample are only significant for the number of suitable applicants but insignificant for the number of applicants. Since firms are only interested in suitable applicants, we think that our main result still holds.

Our results strongly support the hypothesis that the PEA ensures that the applications of suitable unemployed workers registered with the PEA are more evenly spread than the applications of suitable workers coming via the private market. In other words the PEA is successful in reducing coordination frictions.

\subsection{Potential Confounding Factors}

Using the within vacancy information to control for vacancy fixed effects implies that confounding factors can only come from the potentially different application behavior of workers searching via the PEA compared to those not searching via the PEA.

\section{Application Behavior of Non-employed Workers}

To get an idea of a potentially confounding factor, suppose for example that those individuals searching via the PEA use over-proportionally often their personal network to search for a job; and suppose that search via the personal network is also characterized by low coordination frictions (more even distribution of applications). In this case the applications coming from individuals searching via the PEA could be more evenly distributed, because these individuals used their personal network overproportionally often.

One can investigate such potentially confounding factors using the search behavior of non-employed workers. The GSOEP contains information on the search channels used by non-employed workers, who have actively searched for a job in the last four weeks. This information is available for the years 2005 to 2007. The results presented below are based on all actively searching individuals, who send at least one application.

The first thing to note is that non-employed workers, who search via the PEA, and non-employed workers, who do not search via the PEA, are very similar in terms of age, work- and unemploymentexperience and education. The main difference is that $90.9 \%$ of all workers actively searching via the PEA are registered with the PEA, while only $70.2 \%$ of those not searching via the PEA are registered with the PEA. The descriptive statistics also show that workers searching via the PEA use on average 3.6 search channels, while workers not searching via the PEA use on average 2.2 search channels. The PEA accounts for one additional search channel, while the other four search channels (job ads, internet, networks, speculative applications) account in almost equal proportions for the 0.4 additional search channels. All descriptive statistics are shown in Table A.4 in the Appendix.

The results of the multivariate regressions in Table 5 show how using the PEA as search channel is associated with the number of search channels used and with the use of other private market search channels. The remaining coefficients of the respective regressions can be found in Table A.5 in the Appendix. 
Table 5: Individuals: Search behavior

The influence of searching via the PEA on ...

\begin{tabular}{lll}
\hline \hline number of search channels & $1.2644^{* * *}$ & $(0.0701)$ \\
job ads & $0.0651^{*}$ & $(0.0354)$ \\
internet & $0.0894^{* * *}$ & $(0.0298)$ \\
personal network & $0.0622^{*}$ & $(0.0334)$ \\
speculative applications & $0.0720^{* * *}$ & $(0.0295)$ \\
\hline \hline
\end{tabular}

Source: German Socio Economic Panel 2005-2007.

Robust standard errors in brackets. ${ }^{* * *}$ indicates $p<0.01 ;{ }^{*} p<0.05$; ${ }^{*} p<0.1$. The coefficients of using the PEA as search channel for the number of search channels used is based on an OLS regression and the coefficients of using the PEA as search channel for the other search channels (job ads, internet, network, speculative application) are based on the marginal effects of probit regressions.

Table 5 shows that those workers, who use the PEA as search channel, will use on average 1.25 search channels more, i.e., they do not only use the PEA as additional search channel, they also use other search channels more often. This result suggests that the PEA does not crowd out private search incentives but in contrast encourages search via other search channels.

The lower part of Table 5 shows that using the PEA as search channel is associated with a significant increase in the use of all other private market search channels like job ads, internet, personal network, and speculative application by $6.2 \%$ to $8.9 \%$. The respective coefficients are not statistically different from each other. This indicates that workers, who use the PEA, do not substitute one search channel for another one, but increase the use of other search channels in equal proportions. This last result is reassuring since it shows that individuals, who search via the PEA, do not use another search channel over-proportionally. This strengthens our identification strategy. ${ }^{11}$

\section{Conclusion}

We analyze empirically the effect of the intermediation services provided by the PEA on the labor market. Using a unique vacancy-level data-set on the number of (suitable) applicants, we find positive effects of the intermediation services on mitigating search frictions. In particular, the market operated by the PEA attains more coordinated job applications compared to other search channels. An important next step would be to investigate how such a coordination mechanism affects the overall labor market outcome, especially in terms of the market wages and worker allocations.

\footnotetext{
${ }^{11}$ The more frequent use of other search channels by those workers using the PEA compared to those not using the PEA can lead to a more even distribution of applications send via the PEA. This is the case if the number of applications that a worker sends approaches the number of available vacancies, since nobody applies twice for the same job (comparable to drawing from an urn without replacement). To see this consider the limiting case where all workers apply to all suitable vacancies. In this case the applications are evenly distributed. Since the increased use of other search channels documented in Table 5 is the result of the intermediation services provided by the PEA (encouragement of search effort), such an effect would be part of the coordination friction reducing effect of the PEA, which we want to identify.
} 
In a companion paper, Holzner and Watanabe (2017) investigate theoretically the implications of having an additional market place with lower coordination frictions. Using a tractable search model they can show that lower coordination frictions in the PEA reduce wage competition and enable registered firms to pay lower wages compared to the private market. Firms have to trade off this advantage against the negative selection of applicants coming through the PEA when deciding whether or not to register their vacancy with the PEA. Their model also suggests that jobs requiring low qualifications are more likely to be registered with the PEA. They test these theoretical predictions empirically and find strong support for them. 


\section{References}

[1] Abbring, J. H., Berg, G. J., and J. C. Ours, (2005), The effect of unemployment insurance sanctions on the transition rate from unemployment to employment, The Economic Journal, 115(505), 602630 .

[2] Addison, J.T. and P. Portugal, (2002), Job search methods and outcomes, Oxford Economic Papers, $54,505-533$.

[3] Albrecht, J., Gautier, P. A., and S. Vroman, (2006), Equilibrium directed search with multiple applications, The Review of Economic Studies, 73(4), 869-891.

[4] Bendel, R. B., Higgins, S. S., Teberg, J. E., and D. A. Pyke, (1989), Comparison of skewness coefficient, coefficient of variation, and Gini coefficient as inequality measures within populations, Oecologia, 78(3), 394-400.

[5] Blau, D.M., and P.K. Robins, (1990), Job search outcomes for the employed and unemployed, Journal of Political Economy, 98 (3), 637-655.

[6] Burdett, K., Shi, S., and R. Wright, (2001), Pricing and matching with frictions, Journal of Political Economy, 109(5), 1060-1085.

[7] Couch, K.A., (1992), New Evidence on the Long-Term Effects of Employment Training Programs, Journal of Labour Economics, 10, 380388.

[8] Cowell, F. A., and E. Flachaire, (2007), Income distribution and inequality measurement: The problem of extreme values, Journal of Econometrics, 141(2), 1044-1072.

[9] Fougère, D., J. Pradel, and M. Roger, (2009), Does the public employment service affect search effort and outcomes?, European Economic Review 53, 846-869.

[10] Galenianos, M., and P. Kircher, (2009), Directed search with multiple job applications, Journal of Economic Theory, 144(2), 445-471.

[11] Gartner, H., and C.L. Holzner, (2015), Wage Posting as a Positive Selection Device: Theory and Empirical Evidence, CESifo Working Paper No. 5494.

[12] Gregg, P., and J. Wadsworth, (1996), How effective are state employment agencies? Jobcentre use and job matching in Britain, Oxford Bulletin of Economics and Statistics, 58 (3), 442-467.

[13] Heckman, J., R. LaLonde, and J. Smith, (1999), The Economics and Econometrics of Active Labor Market Programs, In Handbook of Labour Economics, edited by O. Ashenfelter, and D. Card, Vol. 3, Amsterdam , North-Holland , 18652097.

[14] Holzer, H.J., (1988), Search method by use by unemployed youth, Journal of Labor Economics,6, $1-20$.

[15] Holzner, C.L., and M. Watanabe, (2017), Understanding the Role of the Public Employment Agency, mimeo.

[16] Hunt, J. (1995), The effect of unemployment compensation on unemployment duration in Germany, Journal of Labor Economics, 88-120.

[17] Katz, L. F., and B. D.Meyer, (1990), The impact of the potential duration of unemployment benefits on the duration of unemployment, Journal of Public Economics, 41(1), 45-72. 
[18] Lalive, R. (2007), Unemployment benefits, unemployment duration, and post-unemployment jobs: A regression discontinuity approach, The American Economic Review, 97(2), 108-112.

[19] Lalive, R., and J. Zweimüller, (2004), Benefit entitlement and unemployment duration: The role of policy endogeneity, Journal of Public Economics, 88(12), 2587-2616.

[20] Lalive, R., Ours, J. C., and J. Zweimüller, (2005), The effect of benefit sanctions on the duration of unemployment, Journal of the European Economic Association, 3(6), 1386-1417.

[21] Lalive, R., Landais, C., and J. Zweimüller, (2015), Market externalities of large unemployment insurance extension programs, The American Economic Review, 105(12), 3564-3596.

[22] Lechner, M., and C. Wunsch, (2009), Are training programs more effective when unemployment is high?, Journal of Labor Economics, 27(4), 653-692.

[23] Lechner, M., Miquel, R., and C. Wunsch, (2011), Longrun effects of public sector sponsored training in West Germany, Journal of the European Economic Association, 9(4), 742-784.

[24] Narendranathan, W., Nickell, S., and J. Stern, (1985), Unemployment benefits revisited, The Economic Journal, 95(378), 307-329.

[25] Nickell, S., and R. Layard, (1999), Labor market institutions and economic performance, Handbook of Labor Economics, 3, 3029-3084.

[26] Osberg, L., (1993), Fishing in different pools: Job-search strategies and job finding success in Canada in the Early 1980s, Journal of Labor Economics, 11, 348-386.

[27] Petrongolo, B., and C. A. Pissarides, (1999), Looking into the Black Box: A Survey of the Matching Function, Journal of Economic Literature, 39, 390-31.

[28] Pissarides, C., (1979), Job Matching with State Employment Agencies and Random Search, The Economic Journal, 89, 818-833.

[29] Shimer, R., (2005), The assignment of workers to jobs in an economy with coordination frictions, Journal of Political Economy, 113(5), 996-1025.

[30] Svarer, M., (2011), The effect of sanctions on exit from unemployment: Evidence from Denmark, Economica, 78(312), 751-778.

[31] Van den Berg, G. J., Van der Klaauw, B., and J. C. Van Ours, (2004), Punitive sanctions and the transition rate from welfare to work, Journal of Labor Economics, 22(1), 211-241.

[32] Weber, A., and H. Mahringer, (2002), Choice and success of job search methods, Empirical Economics, 35, 153-178.

[33] Wielgosz, J.B., and S. Carpenter (1987), The effectiveness of alternative methods of searching for jobs and finding them: An exploratory analysis of the data bearing upon the ways of coping with joblessness, American Journal of Economics and Sociology, 46 (2), 151-164. 


\section{A Appendix: Tables}

Table A.1: Vacancies: PEA used as search and hiring channel (descriptive statistics)

\begin{tabular}{lcc}
\hline \hline & $\begin{array}{c}\text { Fraction of vacancies } \begin{array}{c}\text { (in }) \\
\text { search channel }\end{array} \\
\text { hiring channel }\end{array}$ \\
\hline \hline all vacancies & 48.3 & 17.3 \\
low qualification & 60.9 & 17.7 \\
medium qualification & 50.3 & 20.7 \\
high qualification & 31.9 & 5.7 \\
occupation specific experience & 47.8 & 16.4 \\
no occupation specific experience & 48.7 & 18.1 \\
permanent & 46.3 & 14.6 \\
temporary & 51.2 & 21.2 \\
full-time & 48.2 & 15.9 \\
part-time & 47.4 & 23.8 \\
weekend-work & 50.6 & 16.8 \\
no weekend-work & 48.4 & 17.9 \\
firm size $(1-19)$ & 53.1 & 22.7 \\
firm size $(20-49)$ & 46.6 & 18.6 \\
firm size $(50-199)$ & 50.2 & 20.2 \\
firm size $(200-499)$ & 46.3 & 14.6 \\
firm size (500 +) & 43.8 & 9.6 \\
\hline \hline
\end{tabular}

Source: German Job Vacancy Survey 2005-2008.

Weighted averages using sampling weights. 
Table A.2: Inequality measures for the number of total applicants coming from the PEA and the private market for different subgroups

\begin{tabular}{|c|c|c|c|}
\hline & \multicolumn{3}{|c|}{ absolute number of applicants } \\
\hline & $\begin{array}{l}\text { Gini-Coefficient } \\
\text { Difference } \\
(1)\end{array}$ & $\begin{array}{l}\text { Variance of logs } \\
\text { Ratio } \\
(2)\end{array}$ & $\begin{array}{c}\text { Coefficient of variation } \\
\text { Ratio } \\
(3)\end{array}$ \\
\hline & \multicolumn{3}{|c|}{ full sample } \\
\hline low qualification & $0.2309^{* * *}$ & $1.6820^{* * *}$ & $1.6976^{* * *}$ \\
\hline medium qualification & 0.1100 & $1.6368^{* * *}$ & $1.6148^{* * *}$ \\
\hline high qualification & -0.0913 & $1.3042^{* * *}$ & $1.3161^{* * *}$ \\
\hline occupation specific exp. (yes) & $0.0732^{*}$ & $1.6542^{* * *}$ & $1.6524^{* * *}$ \\
\hline occupation specific exp. (no) & $0.1387^{*}$ & $1.6697^{* * *} *$ & $1.6865^{* * *}$ \\
\hline permanent & $0.1002^{* *}$ & $1.641^{* * *}$ & $1.6327^{* * *}$ \\
\hline temporary & $0.1205^{*}$ & $1.7084^{* * *}$ & $1.7416^{* * *}$ \\
\hline full-time & $0.1942^{* * *}$ & $1.8782^{* * *}$ & $1.8665^{* * *}$ \\
\hline part-time & -0.1306 & 1.0556 & 1.061 \\
\hline weekend-work (yes) & $2.2401^{* * *}$ & $1.3939 * * *$ & $1.3767^{* * *}$ \\
\hline weekend-work (no) & 0.0675 & $1.7192 * * *$ & $1.7367^{* * *}$ \\
\hline firm size $(1-19)$ & $0.0698^{*}$ & $1.3748^{* * *}$ & $1.3314^{* * *}$ \\
\hline firm size $(20-49)$ & $0.1552^{* * *}$ & $1.5786^{* * *}$ & $1.5243^{* * *}$ \\
\hline firm size $(50-199)$ & $0.1452^{* * *}$ & $1.8121^{* * *}$ & $1.7154^{* * *}$ \\
\hline firm size $(200-499)$ & -0.1384 & 0.8625 & 0.8465 \\
\hline \multirow[t]{2}{*}{ firm size $(500+)$} & 0.1101 & $2.0857^{* * *}$ & $2.3048^{* * *}$ \\
\hline & \multicolumn{3}{|c|}{ restricted sample } \\
\hline low qualification & $0.0299^{* * *}$ & 1.0712 & 1.0669 \\
\hline medium qualification & $0.2277^{* * *}$ & $1.9831^{* * *}$ & $1.9263^{* * *}$ \\
\hline high qualification & -0.1014 & $1.3158^{* * *}$ & $1.3636^{* * *}$ \\
\hline occupation specific exp. (yes) & 0.0410 & $1.6469^{* * *}$ & $1.6836^{* * *}$ \\
\hline occupation specific exp. (no) & $0.2759 * * *$ & $1.7471^{* * *}$ & $1.7088^{* * *}$ \\
\hline permanent & $0.0865^{*}$ & $1.6747^{* * *}$ & $1.7080^{* * *}$ \\
\hline temporary & $0.2437 * * *$ & $1.8265^{* * *}$ & $1.7863^{* * *}$ \\
\hline full-time & $0.1797^{* * *}$ & $1.7796^{* * *}$ & $1.7996^{* * *}$ \\
\hline part-time & 0.0147 & $1.5041^{* * *}$ & $1.4802^{* * *}$ \\
\hline weekend-work (yes) & $0.2342^{* * *}$ & $1.2679^{* *}$ & $1.2936^{* * *}$ \\
\hline weekend-work (no) & $0.1600^{* * *}$ & $2.0039^{* * *}$ & $1.9687^{* * *}$ \\
\hline firm size $(1-19)$ & 0.0506 & $1.3227^{* * *}$ & $1.3096^{* * *}$ \\
\hline firm size $(20-49)$ & $0.1769^{* * *}$ & $1.7933^{* * *}$ & $1.7567^{* * *}$ \\
\hline firm size $(50-199)$ & $0.1582^{* *}$ & $1.9520^{* * *}$ & $1.8191^{* * *}$ \\
\hline firm size $(200-499)$ & $0.1173^{* *}$ & 1.1280 & 1.1204 \\
\hline firm size $(500+)$ & 0.1033 & $1.9921^{* * *}$ & $2.2510^{* * *}$ \\
\hline
\end{tabular}

Source: German Job Vacancy Survey 2005-2008.

The full sample contains 3974 observations for the number of applicants and 3653 observations for the number of suitable applicants. For the restricted sample the numbers are respectively given by 2283 and 2092. All measures are calculated using sampling weights. The t-test $\left(\mathrm{H}_{0}\right.$ : Difference $\left.=0\right)$ is based on the standard error, which are provided in the parentheses. Variance-ratio-test $\left(\mathrm{H}_{0}\right.$ : Ratio $\left.=1\right)$ is based on the F-statistic with the degree of freedom given by the respective number of observations minus 1 . *** indicates $p<0.01 ; * * p<0.05 ;{ }^{*} p<0.1$. 
Table A.3: Inequality measures for the number of suitable applicants coming from the PEA and the private market for different subgroups

\begin{tabular}{|c|c|c|c|}
\hline & \multicolumn{3}{|c|}{ absolute number of suitable applicants } \\
\hline & $\begin{array}{l}\text { Gini-Coefficient } \\
\text { Difference } \\
\text { (1) }\end{array}$ & $\begin{array}{c}\text { Variance of logs } \\
\text { Ratio } \\
(2)\end{array}$ & $\begin{array}{l}\text { Coefficient of variation } \\
\text { Ratio } \\
(3)\end{array}$ \\
\hline & \multicolumn{3}{|c|}{ full sample } \\
\hline low qualification & 0.1252 & $1.4431^{* * *}$ & $1.3281^{* * *}$ \\
\hline medium qualification & $0.1495^{* * *}$ & $1.4094^{* * *}$ & $1.2605^{* * *}$ \\
\hline high qualification & $0.1517^{* * *}$ & $2.2055^{* * *}$ & $1.7494^{* * *}$ \\
\hline occupation specific exp. (yes) & $0.0795^{* * *}$ & $1.3288^{* * *}$ & $1.213^{* * *}$ \\
\hline occupation specific exp. (no) & $0.1916^{* * *}$ & $1.7794^{* * *}$ & $1.5213^{* * *}$ \\
\hline permanent & $0.1130^{* * *}$ & $1.4544^{* * *}$ & $1.2841^{* * *}$ \\
\hline temporary & $0.1948^{* * *}$ & $1.7735^{* * *}$ & $1.5386^{* * *}$ \\
\hline full-time & $0.1962^{* * *}$ & $1.7036^{* * *}$ & $1.4530^{* * *}$ \\
\hline part-time & 0.0251 & $1.1687^{* *}$ & $1.1184^{*}$ \\
\hline weekend-work (yes) & 0.0931 & 1.0516 & 1.0361 \\
\hline weekend-work (no) & $0.1827^{* * *}$ & $1.7545^{* * *}$ & $1.4920^{* * *}$ \\
\hline firm size $(1-19)$ & $0.1237^{* *}$ & $1.3398^{* * *}$ & $1.2042^{* * *}$ \\
\hline firm size $(20-49)$ & $0.0903^{* *}$ & $1.2194^{* * *}$ & $1.1483^{* *}$ \\
\hline firm size $(50-199)$ & $0.0596^{*}$ & $1.2056^{* * *}$ & $1.1339^{* *}$ \\
\hline firm size $(200-499)$ & 0.0242 & 1.0355 & 1.0238 \\
\hline \multirow[t]{2}{*}{ firm size $(500+)$} & 0.1242 & $2.1802^{* * *}$ & $1.8896^{* * *}$ \\
\hline & \multicolumn{3}{|c|}{ restricted sample } \\
\hline low qualification & -0.1321 & 0.7008 & 0.7773 \\
\hline medium qualification & $0.1755^{* * *}$ & $1.4475^{* * *}$ & $1.2875^{* * *}$ \\
\hline high qualification & $0.1251^{* *}$ & $1.9833^{* * *}$ & $1.5950^{* * *}$ \\
\hline occupation specific exp. (yes) & $0.0817^{* *}$ & $1.3548^{* * *}$ & $1.2325^{* * *}$ \\
\hline occupation specific exp. (no) & 0.1190 & $1.3219^{* * *}$ & $1.2154^{* * *}$ \\
\hline permanent & $0.1189^{* *}$ & $1.5029^{* * *}$ & $1.3116^{* * *}$ \\
\hline temporary & 0.1231 & $1.3122^{* * *}$ & $1.2175^{* * *}$ \\
\hline full-time & $0.1550^{* * *}$ & $1.4788^{* * *}$ & $1.3082^{* * *}$ \\
\hline part-time & -0.0114 & 1.0244 & 1.0173 \\
\hline weekend-work (yes) & 0.0921 & 1.0622 & 1.0472 \\
\hline weekend-work (no) & $0.1169^{* * *}$ & $1.4517^{* * *}$ & $1.2917^{* * *}$ \\
\hline firm size $(1-19)$ & $0.1858^{* *}$ & $1.5220^{* * *}$ & $1.3206^{* * *}$ \\
\hline firm size $(20-49)$ & $0.1443^{* *}$ & $1.3693^{* * *}$ & $1.2581^{* * *}$ \\
\hline firm size $(50-199)$ & 0.0172 & 1.1048 & 1.0669 \\
\hline firm size $(200-499)$ & 0.0059 & 0.8737 & 0.9126 \\
\hline firm size $(500+)$ & 0.0610 & $1.5758^{* * *}$ & $1.4131^{* * *}$ \\
\hline
\end{tabular}

Source: German Job Vacancy Survey 2005-2008.

The full sample contains 3974 observations for the number of applicants and 3653 observations for the number of suitable applicants. For the restricted sample the numbers are respectively given by 2283 and 2092. All measures are calculated using sampling weights. The t-test $\left(\mathrm{H}_{0}\right.$ : Difference $\left.=0\right)$ is based on the standard error, which are provided in the parentheses. Variance-ratio-test $\left(\mathrm{H}_{0}:\right.$ Ratio $\left.=1\right)$ is based on the F-statistic with the degree of freedom given by the respective number of observations minus 1 . *** indicates $p<0.01 ;{ }^{* *} p<0.05 ;{ }^{*} p<0.1$. 
Table A.4: Worker characteristics (descriptive statistics)

\begin{tabular}{lccc}
\hline \hline & $\begin{array}{c}\text { Characteristics of } \\
\text { all }\end{array}$ & $\begin{array}{c}\text { non-eyed actively searching individuals } \\
\text { via the PEA }\end{array}$ & \begin{tabular}{c} 
without the PEA \\
\hline \hline number of search channels
\end{tabular} \\
PEA (search channel) & 3.3 & 3.6 & 2.2 \\
Job ads (search channel) & $75.5 \%$ & $100 \%$ & $0 \%$ \\
Internet (search channel) & $83.0 \%$ & $85.5 \%$ & $75.1 \%$ \\
Network (search channel) & $62.0 \%$ & $64.9 \%$ & $53.2 \%$ \\
Speculative appl. (search channel) & $72.4 \%$ & $73.4 \%$ & $69.3 \%$ \\
registered unemployed & $35.1 \%$ & $38.4 \%$ & $24.8 \%$ \\
female & $85.8 \%$ & $90.9 \%$ & $70.2 \%$ \\
age & $50.6 \%$ & $47.8 \%$ & $59.0 \%$ \\
work experience (full-time) & $38.3 \mathrm{yrs}$ & $38.0 \mathrm{yrs}$ & $39.4 \mathrm{yrs}$ \\
work experience (part-time) & $10.7 \mathrm{yrs}$ & $10.8 \mathrm{yrs}$ & $10.4 \mathrm{yrs}$ \\
unemployment experience & $1.6 \mathrm{yrs}$ & $1.5 \mathrm{yrs}$ & $1.8 \mathrm{yrs}$ \\
inadequate education & $3.4 \mathrm{yrs}$ & $3.4 \mathrm{yrs}$ & $3.6 \mathrm{yrs}$ \\
general elementary & $2.8 \%$ & $2.8 \%$ & $2.9 \%$ \\
middle vocational & $15.8 \%$ & $15.6 \%$ & $16.2 \%$ \\
vocational \& high school & $55.7 \%$ & $55.6 \%$ & $56.2 \%$ \\
higher vocational & $4.3 \%$ & $4.3 \%$ & $4.4 \%$ \\
higher education & $5.6 \%$ & $6.5 \%$ & $2.9 \%$ \\
\hline \hline
\end{tabular}

Source: German Job Vacancy Survey 2005-2007.

Weighted averages using sampling weights. 
Table A.5: The influence of the PEA search channel on search behavior

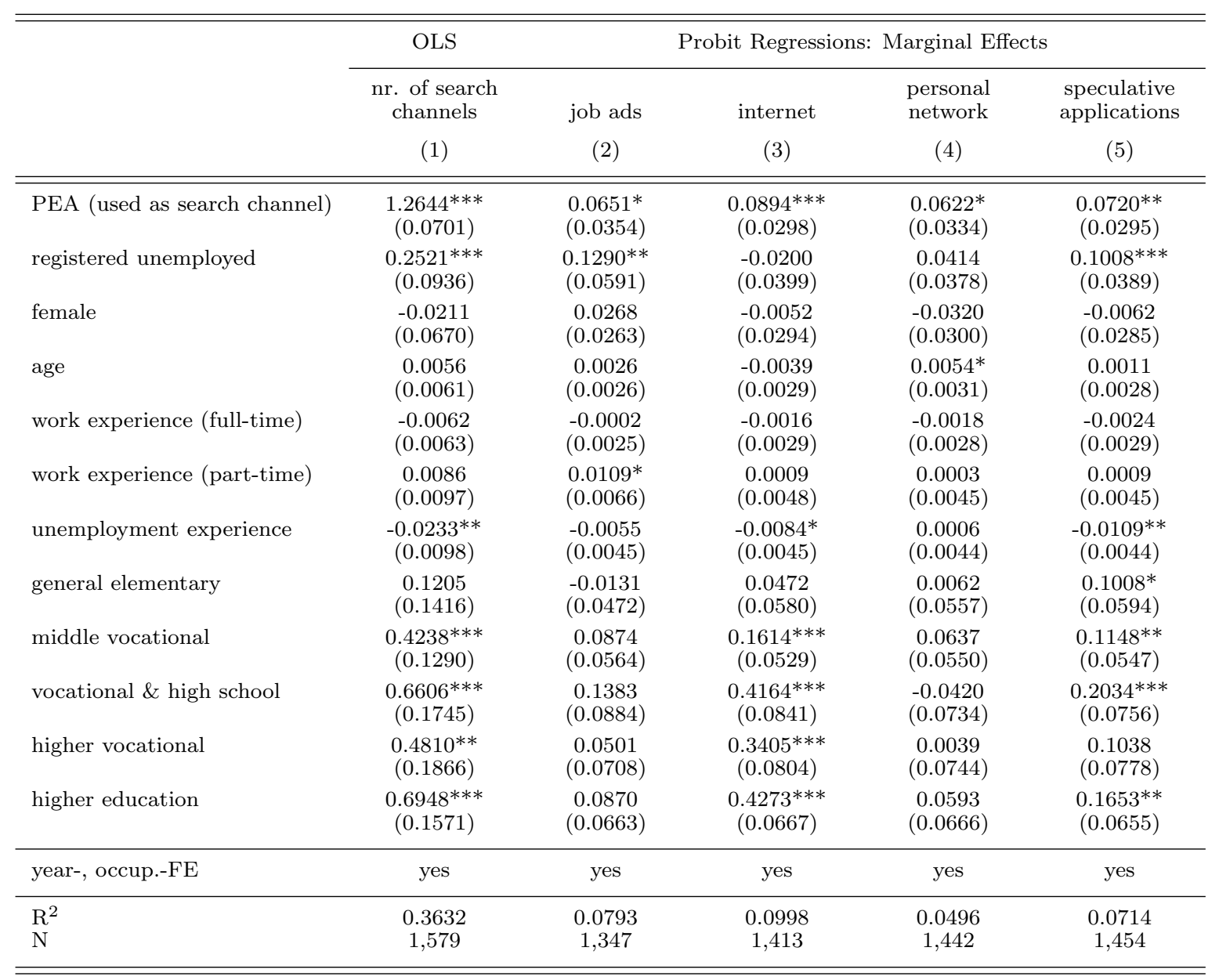

Source: German Socio Economic Panel 2005-2007.

Robust standard errors in brackets. ${ }^{* * *}$ indicates $p<0.01 ;{ }^{* *} p<0.05 ;{ }^{*} p<0.1$. 